\section{Multiplication in specialization}

\author{
Julian Davies
}

Journal of Biotechnology. Managing editor A. Fiechter. Elsevier. 12/yr. Dfl. $861, \$ 347$.

Biotechnology Progress: A Journal of Food, Pharmaceutical and Bioengineering. Editor M. L. Shuler. American Institute of Chemical Engineers. 4/yr. US \$50; elsewhere $\$ 55$.

MIRCEN Journal of Applied Microbiology and Biotechnology: A Research Journal for Biotechnology in the Developing World. Editors J.C. Senez and F.A. Skinner. Oxford University Press. 4/yr. UK £20; North America \$45; elsewhere £25.

THERE are now many journals and review series devoted to biotechnology, a specialization which is apparently being strengthened by the attitudes of editors of the more established scientific journals who narrow perspectives by not accepting papers that are "too applied, too technical, too commercial etc". Comparatively few publications attempt to present a broad spectrum of biological sciences these days.

Given this situation of exclusivity, it is not surprising that specialized biotechnology journals have mushroomed. Provided that they maintain good scientific standards with peer review, their presence is welcome and fills an important need. Within biotechnology journals there is also specialization with respect to subject area and, obviously, readership. These three recent additions to the roster differ greatly in philosophy and level of scientific acceptability, but they would all appear to fill a need.

Of the three, the Journal of Biotechnol$o g y$ has the most expansive approach and is produced for profit by a well-known scientific publisher. It is also the most expensive: at nearly 12 cents (US) a page its price is inflated compared to many of the more popular scientific journals (PNAS, Nature, Cell, EMBO Journal all work out at about 5 cents per page). Journal of Biotechnology extends its outlook by providing useful reviews (on protein secretion systems, for example) as well as original articles. The review period is surprisingly short, and is often as little as 4 days!

In its instructions to authors, the journal makes an unusual comment: "fermentation has become a very ambiguous expression very popular in English-speaking countries. Therefore it should not be used in this journal". Why such censorship? Is "fermentation" now a naughty word?

Biotechnology Progress is a publication of the American Institute of Chemical Engineers and is one of the most specialized

of the available biotechnology journals, being directed towards engineers solely, with many technical illustrations. It contains much technology and almost no biology; it is exclusively concerned with the problems of reactors, separation techniques, downstream processing and so on, and the papers are of a high standard and well-presented. No review period is indicated. It is not an international journal in the issues examined, all the authors were at institutions in the United States. This is not the case for what is probably the leading journal in the field, Biotechnology and Bioengineering, published by Wiley, which also has a much broader purview.

MIRCEN Journal of Applied Microbiology and Biotechnology is published for UNESCO by Oxford University Press. It is a research journal devoted to topics relevant to the needs of the developing world and covers all aspects of the practical applications of biotechnology: food, medicine, environment, energy, waste, insect control etc. Included are occasional review papers pertinent to its

\section{Sense of biology}

\section{A. Martin Smith}

Biosensors: An International Journal. Managing editors I.J. Higgins, W.G. Potter and A.P.F. Turner. Elsevier Applied Science. 6/yr. UK $£ 80$; elsewhere $£ 88$.

THE area of research and development which has become known as "biosensors" draws upon a very broad range of disciplines, from physics, electrical engineering and electrochemistry, through to microbiology, biochemistry and immunology. In consequence publications in this area have been spread across a number of journals, and there has been no single journal devoted to the subject.

Biosensors seeks to rectify this problem. The introductory editorial states: "We intend that Biosensors should provide a focus for review articles, informed comment, original papers and news items". Furthermore, the definition of biosensors chosen is deliberately loose and includes optoelectronic as well as electrode devices, and the initial articles have included a paper on the use of quadrupole mass spectrometry in the monitoring and control of fermentation.

At least in the first four issues, the emphasis has been on relatively long review articles giving a comprehensive grounding in the main areas of current biosensor research. Topics covered include basic concepts, the estimation of biomass, amperometric sensors and optoelectronic immunosensors. More specific articles on urea and glucose brief, for example on mycobacterial disease; in this article it is pointed out that there are ten million new cases of $\mathrm{TB}$ every year and some three million deaths worldwide. (Why doesn't TB get the same attention as AIDS?) This journal serves as a means of disseminating UNESCO and other resource information, which may in fact be its major utility; its scientific base is broad and this journal would not attract research papers of state-of-the art urgency.

It would seem that the available biotechnology journals now cover all experimental aspects of the subject, from the killing of flies in toilets in West Africa with bacterial toxins, to new expression vectors, to designing multimembrane bioreactors. Whether there is justification for continued multiplication in this area is debatable, since as evidenced by these journals the fruits become less and less tasty.

Julian Davies is Professor in and Head of the Microbial Engineering Unit in the Department of Biotechnology, Institut Pasteur, 25 rue du Docteur Roux, 75724 Paris, France.

measurement electrodes, and sensors for hydroponics have also been published. The success of biosensor devices depends ultimately on the ability of industry to make sensors with reproducible and reliable performance, and at a price which allows viable commercial use. This need has been recognized explicitly in one of the papers published and it is to be hoped that further articles will expand on this theme in specific sensor areas.

The journal is of small format $(165 \mathrm{x}$ $240 \mathrm{~mm}$ ) but the print size is relatively large and clear, as are the reproductions of figures. The editors' declared aim is that Biosensors should be international, and that as it matures there should be more

\section{Biosensors \\ AN INTERNATIONAL JOURNAL}

original papers, news items, book reviews, conference and meeting reports, and letters to the editors. The journal can certainly claim to be European but no articles from the United States or Japan were published in the first issues, although influential researchers from both of these countries are represented on the editorial board. Similarly, only articles have been published so far. The ultimate success of the journal will depend on it expanding its scope and in this respect it certainly deserves to succeed on the basis of the quality of the initial papers.

A. Martin Smith is Head of the Biosensors Section at Unilever Research, Colworth Labora. tory, Sharnbrook, Bedford MK44 1LQ,UK. 